\title{
Application of Multi-step Differential Transformation Method (Ms-DTM) for Solving Nonlinear Problem of Heat Transfer in Solar Air Collector
}

\author{
Ismail Tabet $^{1 *}$, Mohamed Kezzar ${ }^{2}$, Meriem Chieul $^{3}$, Nouredin Nafir ${ }^{3}$, Abelkader Khentout ${ }^{4}$ \\ ${ }^{1}$ Physical Engineering Department, University 20 Août 1955 of skikda, B.P.26, route d'El- Hadaiek, 21000, Algeria \\ ${ }^{2}$ Mechanical Engineering Department, University 20 Août 1955 of skikda, B.P.26, route d'El- Hadaiek, 21000, Algeria \\ ${ }^{3}$ Electrical Engineering Department, University 20 Août 1955 of skikda, B.P.26, route d' El- Hadaiek, 21000, Algeria \\ ${ }^{4}$ Drilling Department and MCP, University of Kasdi Merbah, Ghardaia Road, BP.511, 30,000 Ouargla, Algeria
}

Corresponding Author Email: tabet21@yahoo.fr

https://doi.org/10.18280/ijht.370214

Received: 8 January 2018

Accepted: 29 April 2019

\section{Keywords:}

solar air collector, thermal efficiency, differential transformation multi-step method, numerical method, Rung- Kutta

\begin{abstract}
In this paper, we have applied differential transformation multi-step analytical method (multi-step differential transformation method) to study the thermal behavior in the solar air collectors. The Results obtained are compared with the numerical solution by Runge-Kutta fourth order method. Then the effects of some parameters such as a mass flow of air and the dimensions of the collector on the thermal performance of the collector are made. The thermal efficiency increases with increasing airflow. The thermal efficiency of solar air collectors decreases with increasing of the solar collector length. The results show the robustness of the multi-step differential transformation method proposed over the standard technique (differential transformation method) and a comparison shows the applicability, reliability and simplicity of the technique used.
\end{abstract}

\section{INTRODUCTION}

Seen importance of clean energy or renewable, has to know wind energy, hydraulics, Biomass, geothermal and solar, in this study one interested in solar energy and their applications and using the advantages of solar energy, during last years a particulate attention was dedicated have the solar collectors have air. Who is usually used for the heating, drying and cooling in the majority of the domestic and industrial applications. For this reason, many researchers are focus with the thermal contribution of the solar air collectors [1-3].

Nonlinear equations in engineering can be solved using many methods [4-7]. Multi-step differential transformation Method (Ms-DTM) is applied to obtain the solutions of various kinds of problems for and PDEs [8-10], Kuo et al. [11] provided analytical solutions of the dynamics distributions of the problem of boundary layer falkenskane in the form of a series of power, a comparison of resulting shows the effectiveness of the DTM method. Khader et al. [12] characterized the flow of a non-Newtonian fluid in a porous environment, and with the presence of a thermal radiation source by differential equations with the PDEs; these equations are transformed into a non-linear system ODEs. The equations obtained are solved analytically by DTM method. The study carried out by Hessameddin [13] visualized good manners the effectiveness of the DTM method to solve a non-linear problem of heat transfer, a comparison was to make between the techniques used DTM with the other methods analytical, namely: Variational iteration method VIM, Homotopy analysis method (HPM).The work carried out by and its teams are successful has bracket the DTM method to determine the distribution of the temperatures inside a solar air collector, this study comprised a comparison thoroughly of the analytical method used (DTM) method, compared to the method of RungeKutta of fourth order, Precision, effectiveness, iteration count and the speed of convergence of the analytical techniques to attract the attention of several researchers who are interested in the development of new algorithms, which improve the behavior of the analytical methods. Hatami et al. [14] developed algorithm represents a differential transformation multi-step method (Ms-DTM), good results manners the advantages of (Ms-DTM) method compared to (DTM) method. Joneidi et al. [15] used (DTM) method to determine fin efficiency of convective straight fins with temperature dependent thermal conductivity, and he compared to exact solution and fourth order Runge-Kutta numerical solution, and showed that the method provides high accuracy DTM to solve the problems of heat transfer in engineering.

The aim of this work is the analytical study of the thermal behavior of a solar air collector using multi-step differential transformation analytical method (Ms-DTM), the results obtained compared with the numerical by Runge Kutta of fourth order method, the effect of some parameters on the performance of solar air collectors are treated.

\section{MATERIALS AND METHODS}

The Figure 1 illustrates a volume control of a solar air collector, and there compose, namely: a cover glass, an absorber plate, an air duct and rear plate. 


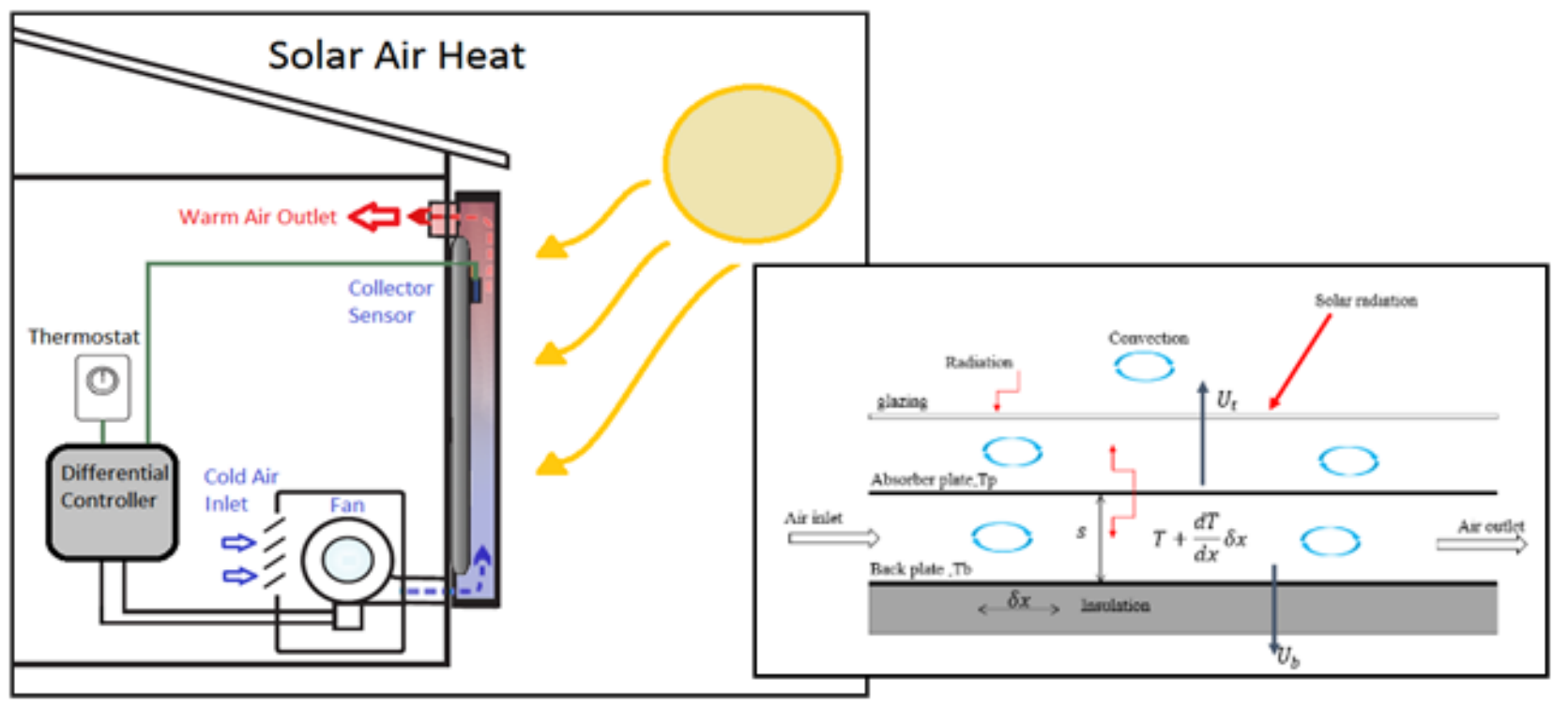

Figure 1. Simple solar air heater

The energy balance of absorber plate is given as follows:

$$
\begin{aligned}
& \mathrm{S}(\mathrm{dx})=U_{t}\left(\mathrm{~T}_{p}-T_{a}\right)+h_{p-a}^{c}(d x)\left(\mathrm{T}_{p}-T\right)+ \\
& h_{p-b}^{r}(\mathrm{dx})\left(T_{p}-T_{b}\right)
\end{aligned}
$$

With: $S=(\alpha \tau) \cdot G_{t}$.

The air energy balance of fluid is given as follows:

$$
\frac{\dot{m}}{W} c_{p}\left(T^{\prime} d x\right)=h_{p-a}^{c}(\mathrm{dx})\left(T_{p}-T\right)+h_{b-a}^{c}(\mathrm{dx})\left(T_{b}-T\right)
$$

The energy balance on the surface of the back plate $(1 \times d x)$ gives

$$
h_{p-a}^{r}(d x)\left(T_{p}-T_{a}\right)=h_{p-a}^{c}(d x)\left(T_{p}-T\right)+U_{b}(d x)\left(T_{b}-T_{a}\right)
$$

Given that, $\mathrm{U}_{\mathrm{b}}$ is much $\mathrm{UT}, \mathrm{U}_{\mathrm{L}} \approx \mathrm{U}_{\mathrm{t}}$ Therefore, $\mathrm{U}_{\mathrm{b}}$ is neglected and Eq. (3) is solved for $\mathrm{T}_{\mathrm{b}}$ :

$$
T_{b}=\frac{h_{p-b}^{r} T_{p}+h_{b-a}^{c} T}{h_{p-b}^{r}+h_{b-a}^{c}}
$$

Substitution of Eq. (4) in Eq. (1) gives

$$
T_{a}\left(U_{L}+h\right)=S+U_{L} T_{a}+h T
$$

With

$$
h=h_{b-a}^{c}+\frac{1}{1 / h_{b-a}^{c}+1 / h_{p-b}^{r}}
$$

Substitution of Eq. (4) into Eq. (2) gives;

$$
h T_{p}=\frac{\dot{m}}{W} c_{p} T^{\prime}+h T
$$

Considering Eqns. (5) and (7), the following equations are obtained

$$
\begin{gathered}
\frac{\dot{m}}{W} c_{p} T^{\prime}=F^{\prime}\left[S-U_{L}\left(T-T_{a}\right)\right] \\
F^{\prime}=\frac{1 / U_{L}}{1 / U_{L}+1 / h}=\frac{h}{h+U_{L}}
\end{gathered}
$$

In all previous mathematical models, we assume that air behaves for an ideal gas with a constant specific heat, which would produce an error in the thermal analysis. In reality, the specific heat of air varies with temperature and this will significantly influence the thermal performance of the collector. A model was presented by a team of researchers called the polynomial equation of NASA [16]. This model has the following formula for the ambient temperature between $200 \mathrm{~K}$ and $1000 \mathrm{~K}$ :

$$
\begin{aligned}
& \frac{C_{p}}{R_{g}}=3.56839-6.788729 \times 10^{-4} T+1.5537 \times 10^{-6} T^{2} \\
& -3.29937 \times 10^{-12} T^{3}-466.395 \times 10^{-15} T^{4}
\end{aligned}
$$

$$
C_{p}=a+b T
$$

where $\mathrm{Rg}$ is the gas constant $(\mathrm{J} / \mathrm{kg} \mathrm{K})$. For low temperatures $(275 \mathrm{~K}-400 \mathrm{~K})$, the specific heat is almost linear [5], that is, a close approximation.

By using the table of physical properties for air at different temperatures in ref. [18], the coefficients " $a$ " and "b" obtained 980.52 and 0.083, respectively. By substituting Eq. (11) into Eq. (8) and rearranging the equation, we obtained the following:

$$
\frac{\dot{m}}{W} a T^{\prime}(x)+\frac{\dot{m}}{W} b T^{\prime}(x) T(x)+F^{\prime} U_{L} T(x)-F^{\prime}\left(S+T_{a} U_{L}\right)
$$

The initial state of the Eq. (12) is 


$$
T=T i, \text { at } . \quad x=0
$$

To calculate the convection heat transfer coefficients, the Reynolds number should be determined.

$$
R_{e}=\frac{\rho V D}{\mu}=\frac{\dot{m} D}{A_{c} \mu}
$$

where $A_{c}=s \times W$ and $D$ is the hydraulic diameter of the channel.

$$
D=4 \frac{W s}{2(W+s)}=2 \frac{W s}{(W+s)}
$$

After determination of the Reynolds number, the coefficients of heat transfer by convection of turbulent flow will be calculated as follows [19]:

$$
h_{p-a}^{c}=h_{b-a}^{c}=\frac{K}{D} 0.0158 R_{e}^{0.8}
$$

The following relation expresses the thermal efficiency of the collector [16-17]:

$$
\eta_{T}=\frac{Q_{u}}{A_{s} G_{t}}=\frac{\dot{m} \int_{T_{i}}^{T_{f}}(a+b T) d T}{(W . L) G_{t}}
$$

\section{MULTI-STEP}

DIFFERENTIAL

\section{TRANSFORMATION METHOD (MS-DTM)}

We consider an ordinary differential equation of $n$ terms this by [14]:

$$
\left\{\begin{array}{l}
x\left(t, x, x^{\prime}, x^{\prime \prime}, \ldots \ldots \ldots, x^{N}\right) \\
x^{k}(0)=\alpha_{k}, k=0,1 \ldots ., N
\end{array}\right.
$$

The theory of differential transformation method (DTM) and extension there (Ms-DTM) are very convenient for solving nonlinear differential equations ordinary or partial. The principle of the (Ms-DTM) method retains the overall shape of the standard method (DTM) the difference lies in the new strategy of differential transformation adopted for operating.

$$
x(t)=\sum_{k=0}^{\infty} \frac{\left(t-t_{i}\right)^{k}}{k !}\left[\frac{d^{k} x(t)}{d t^{k}}\right]_{t=t_{i}}
$$

When $t_{i}=0$ the form of equation (18) is a private event of the form:

$$
x(t)=\sum_{k=0}^{\infty} \frac{t^{k}}{k !}\left[\frac{d^{k} x(t)}{d t^{k}}\right]_{t=0}
$$

Differential processing of the function $\mathrm{x}(\mathrm{t})$ is expressed by:

$$
X(k)=\sum_{k=0}^{\infty} \frac{H^{k}}{k !}\left[\frac{d^{k} x(t)}{d t^{k}}\right]_{t=0}
$$

where $\mathrm{x}(\mathrm{t})$ is the original function, $\mathrm{X}(\mathrm{k})$ is the transformed function and $\mathrm{H}$ is a constant. Reverse differential processing of the function $\mathrm{X}(\mathrm{k})$ is given by:

$$
x(t)=\sum_{k=0}^{\infty}\left(\frac{t}{H}\right)^{k} X(k)
$$

The functions are determined from the boundary conditions or initial conditions.

Mathematical operators carried out by the method (MsDTM) will be represented in the Table 1 .

Table 1. The basic operations on the two methods of DTM and Ms-DTM [10]

\begin{tabular}{ccc}
\hline $\begin{array}{c}\text { Original } \\
\text { function }\end{array}$ & DTM & Ms-DTM \\
\hline $\boldsymbol{f}(\boldsymbol{t})=\boldsymbol{g}(\boldsymbol{t}) \pm \boldsymbol{s}(\boldsymbol{t})$ & $F(t)=G(t) \pm S(t)$ & $F(t)=G(t) \pm S(t)$ \\
\hline $\boldsymbol{f}(\boldsymbol{t})=\boldsymbol{c g}(\boldsymbol{t})$ & $F(t)=c G(t)$ & $F(t)=c G(t)$ \\
\hline$f(t)=\frac{d^{n} g(t)}{d t^{n}}$ & $F(k)=\frac{(k+n) !}{k !} G(k+n)$ & $F(k)=\frac{(k+n) !}{H^{n} k !} G(k+n)$ \\
\hline$f(t)=g(t) s(t)$ & $F(k)=\sum_{r=0}^{k} G(r) S(k-r)$ & $F(k)=\sum_{r=0}^{k} G(r) S(k-r)$ \\
\hline$f(t)=x^{n}$ & $F(k)=\delta(k-n)$ & $F(k)=\delta(k-n)$ \\
$=\left\{\begin{array}{lll}0 & \text { if } & k \neq n \\
1 & \text { if } & k=n\end{array}\right.$ & $=\left\{\begin{array}{lll}0 & \text { if } \mathbb{R} \neq n \\
1 & \text { if } \mathbb{R}=n\end{array}\right.$ \\
\hline
\end{tabular}

\section{IMPLEMENTATION OF MULTI-STEP DIFFERENTIAL TRANSFORMATION METHOD}

It was applied to determine the temperature distribution and thermal efficiency.

We can rewrite the equation (12-a) in the form:

$$
T^{\prime}+\frac{b}{a} T T^{\prime}+F^{p} U_{l} T-F^{p}\left(S+T_{a} U_{l}\right)=0
$$

Taking $\mathrm{T}$ factor in coma

$$
\left(1+\frac{b}{a} T\right) T^{\prime}+F^{p} U_{l} T-F^{p}\left(S+T_{a} U_{l}\right)=0
$$

Using Table 1 equation 12 becomes of the following form:

$$
\begin{aligned}
& (k+1)\left(1+\frac{b}{a} T(k)\right) T(k+1)+F^{p} U_{l} T(k)- \\
& F^{p}\left(S+T_{a} U_{l}\right) \delta(k)=0
\end{aligned}
$$

With 


$$
\delta(k)= \begin{cases}0 & \text { if } k \neq 0 \\ 1 & \text { if } k=0\end{cases}
$$

The iterative relationship of the temperature distribution from the (Ms-DTM) method given by:

$$
\left\{\begin{array}{c}
T(k+1)=\frac{1}{(k+1) H^{1}\left(1+\frac{b}{a} T(k)\right)}\left\{\begin{array}{l}
-F^{p} U_{l} T(k)+ \\
F^{p}\left(S+T_{a} U_{l}\right) \delta(k)
\end{array}\right\} \\
k=0,1,2,3 \ldots \ldots \ldots . N
\end{array}\right.
$$

From the boundary condition presented by the equation. (12-b) is obtained

$$
T(0)=T_{i}\left(T_{i}=323\right)
$$

The components of the solution of the temperature distribution according to the method (Ms-DTM) are expressed by:

$$
T(1)=25.0141 \mathrm{H}
$$

$$
T(2)=\frac{2.4416046857715545 \mathrm{H}^{2}}{1.027341614653449+0.00211742117653457 \mathrm{H}}
$$

$$
T(3) \frac{785.781194542424 H^{3}}{-5219.844528788592+(-21.516911581944292+H) H}
$$

$$
\begin{aligned}
& A_{1}=(-114851.03601998372-236.71582300078663 \mathrm{H}) \mathrm{H}^{4} \\
& A_{2}=(33.237698925521414+\mathrm{H})(203.95995769022028+\mathrm{H}) \\
& A_{3}=2369.0276740862464+(-63.35957124194878+\mathrm{H}) \mathrm{H} \\
& T(4)=A_{1} /\left(A_{2} A_{3}\right)
\end{aligned}
$$

Finally, and after a certain number of iterations, the solution of equation (12-a) by the Ms-DTM method is given by:

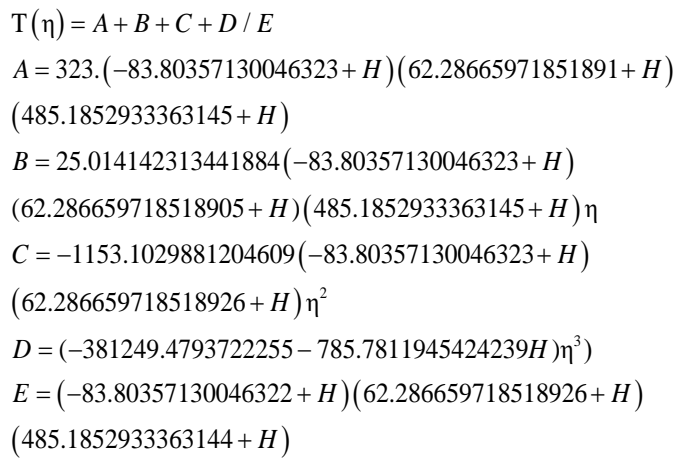

\section{RESULTS AND DISCUSSIONS}

The temperature distribution in solar air collectors, governed by nonlinear ordinary differential equation of the first order (Eq. 7), this equation was solved numerically by the Runge-Kutta method of order four and analytically by a new approach called the differential multi-step processing method (Ms-DTM). The thermo-physical properties of the air are shown in Table 2.

Table 2. The thermo-physical properties of the air

\begin{tabular}{cccc}
\hline Parameter & value & Parameter & value \\
\hline $\boldsymbol{a}$ & 980.52 & $G_{t}$ & $890, w \cdot \mathrm{m}^{-2}$ \\
\hline $\boldsymbol{b}$ & 0.083 & $T_{a}$ & $323, \mathrm{k}$ \\
\hline $\boldsymbol{s}$ & $0.015(\mathrm{~m})$ & $m$ & $0.06, K g \cdot \mathrm{s}^{-1}$ \\
$\boldsymbol{h}_{\boldsymbol{r}, \boldsymbol{p}-\boldsymbol{b}}$ & $7.395\left(\mathrm{~W} \cdot \mathrm{m}^{-2} \mathrm{k}^{-1}\right)$ & $W$ & $1.2, \mathrm{~m}$ \\
\hline $\boldsymbol{\mu}$ & $2.051 \times 10^{-5}, \mathrm{Kg} \cdot \mathrm{m}^{-1} \cdot \mathrm{s}^{-1}$ & $U_{l}$ & $6.5, W \cdot \mathrm{m}^{-2} \cdot \mathrm{k}^{-1}$ \\
\hline $\boldsymbol{k}$ & $0.029\left(\mathrm{~W} \cdot \mathrm{m}^{-1} \cdot \mathrm{K}^{-1}\right)$ & $\tau \alpha$ & 0.9 \\
\hline
\end{tabular}

From the Figure 2, it is clearly demonstrated that wander in case $\mathrm{H}$ takes the value $(\mathrm{H}=-3.87812)$ is significantly lower than the other case $(\mathrm{H}=1,-3.46302$, and -3.66571$)$, firstly, and secondly it very clear in the table (2) the accuracy of the Ms-DTM method strongly held to the value of the constant $\mathrm{H}$. This constant takes different values from 1 in which the method converges rapidly with high accuracy (the roam becomes small).

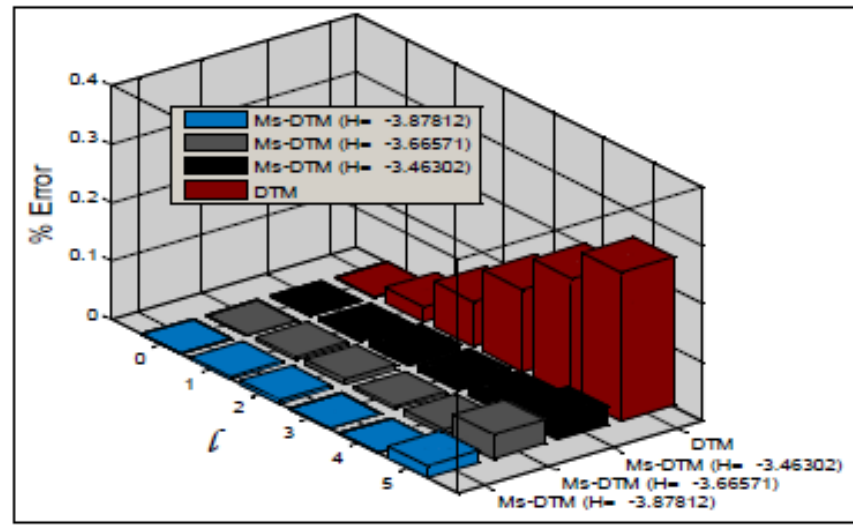

Figure 2. Effects of constant $\mathrm{H}$ on the variation of error for the different analytical methods

Table 3. Comparison between numerical and analytical results of the temperature distribution of the sensor when $\mathrm{W}=0.6$ and $\mathrm{m}=0.02$

\begin{tabular}{cccccc}
\hline $\boldsymbol{\eta}$ & $\begin{array}{c}\text { Numerical } \\
\text { RK4 }\end{array}$ & $\begin{array}{c}\text { DTM } \\
\text { H=1 }\end{array}$ & $\begin{array}{c}\text { Ms-DTM } \\
\text { H=-3.463 }\end{array}$ & $\begin{array}{c}\text { Ms-DTM } \\
\text { H=-3.665 }\end{array}$ & $\begin{array}{c}\text { Ms-DTM } \\
\text { H=-3.878 }\end{array}$ \\
\hline $\mathbf{5 . 0 0}$ & 403.549 & 403.803 & 403.518 & 403.508 & 403.529 \\
\hline $\mathbf{4 . 0 0}$ & 392.929 & 393.13 & 392.913 & 392.921 & 392.929 \\
\hline $\mathbf{3 . 0 0}$ & 380.089 & 380.229 & 380.1 & 380.094 & 380.089 \\
\hline $\mathbf{2 . 0 0}$ & 364.558 & 364.635 & 364.569 & 364.566 & 364.563 \\
\hline $\mathbf{1 . 0 0}$ & 345.761 & 345.786 & 345.766 & 345.766 & 345.765 \\
\hline $\mathbf{0 . 0 0}$ & 323.00 & 323.00 & 323.00 & 323.00 & 323.00 \\
\hline
\end{tabular}

In Figure 3, we looked at the effect of the width of the sensor on the distribution of the collector temperatures when $\mathrm{m}=0.08$. It is clearly seen in this figure that there is a proportional relationship between the temperature distribution and the width of the sensor "W".

The air mass flow effect on the distribution of the collector temperature is visualized in Figure 4 when $\mathrm{W}=0.6$ is observed that the temperature distribution decreases with increase of air mass flow " $\mathrm{m}$ " and the highest temperature is shown at the collector extremity.

Finally, it was investigated the effects of the mass flow of air and the length of the thermal efficiency of solar collectors. Which are illustrated in the Figures 5- 6, for different values 
of mass flow of air and the length of the collector.

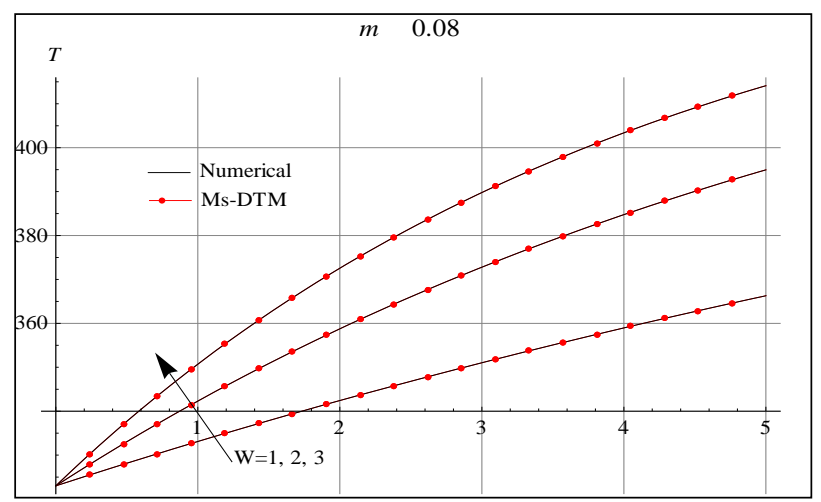

Figure 3. Effect of the length of the collector on the temperature profile for $\mathrm{m}=0.08$

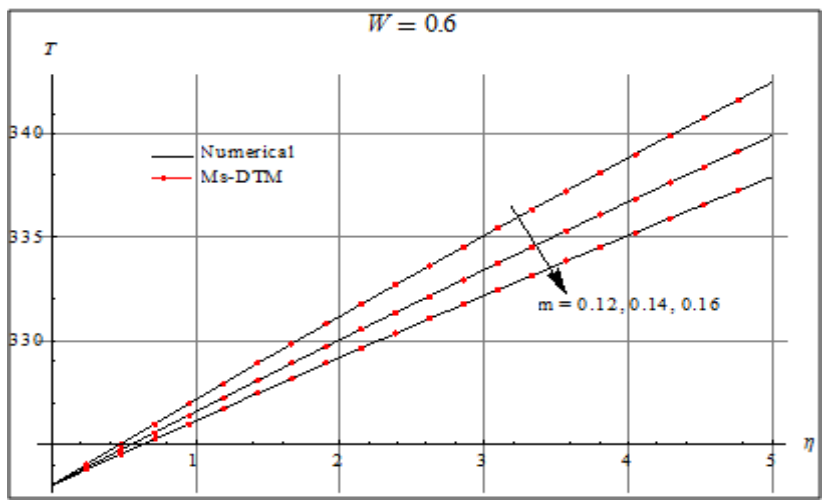

Figure 4. Effect of mass flow on the temperature profile for $\mathrm{w}=0.6$

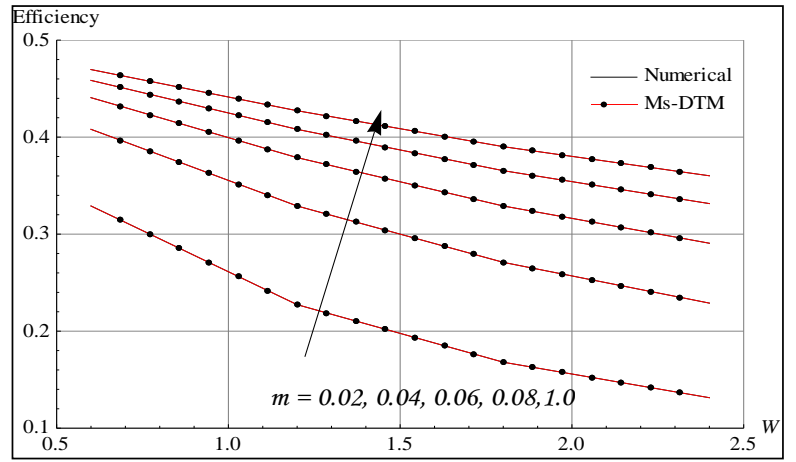

Figure 5. Variation of the thermal efficiency based on the collector length for various values of mass flow of air

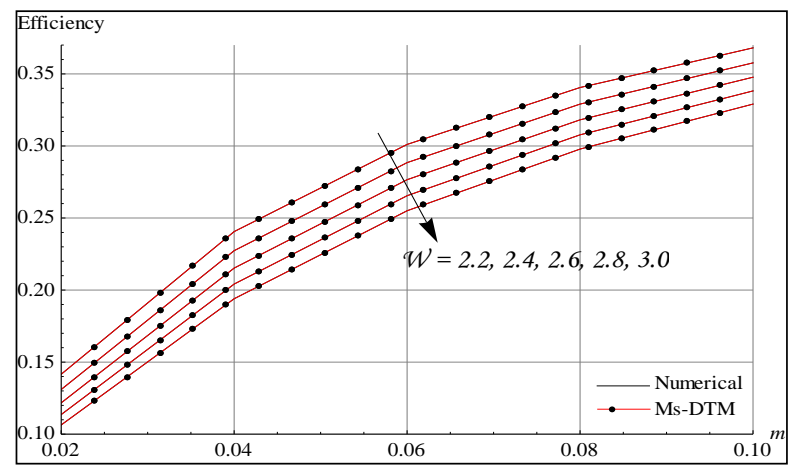

Figure 6. Variation of thermal efficiency as a function of mass flow for different values of the length of the sensor
According to figures viewed, it is clear that the thermal efficiency of the sensor takes high values for high airflow (the thermal efficiency increases with increasing mass flow) and therefore the heat useful $(\mathrm{Qu})$ will be diminished. But against the dimensions of the collector affected negatively on thermal efficiency.

\section{CONCLUSION}

In this article, we will cover a thermal study of a solar air. We start with the mathematical formulation of the problem studied, then we solve the nonlinear ordinary differential equation of the first order that characterizes the temperature distribution numerically by the Runge Kutta analytically and a new approach was applied to solve the problem considered (Ms-DTM). We then show the advantage of the technique used (Ms-DTM) than the standard technique (DTM) and the effects of parameters, namely airflow sensor and the length of the thermal efficiency of solar air collector was done.

The main conclusions to be drawn from this study are:

- The thermal efficiency increases with increasing airflow.

- Increasing the sensor length is decreasing thermal efficiency.

- The results show the robustness of the method (MsDTM) proposed over the standard technique (DTM) and a comparison shows the applicability, reliability and simplicity of the technique used.

- The presence of the constant $\mathrm{H}$ in the solution provided by the new approach (Ms-DTM) consequently increase the efficiency of the new method approach (Ms-DTM) in terms of accuracy and convergence rate (decreased the number of iterations).

\section{REFERENCES}

[1] Alkilani, M.M., Sopian, K., Alghoul, M.A., Sohif, M., Ruslan, M.H. (2011). Review of solar air collectors with thermal storage units. Renewable and Sustainable Energy Reviews, 15(3): 1476-1490. https://doi.org/10.1016/j.rser.2010.10.019

[2] Gulcimena, F., Karakaya, H., Durmus, A. (2016). Drying of sweet basil with solar air collectors. Renewable $\quad$ Energy, 93 : 7786. https://doi.org/10.1016/j.renene.2016.02.033

[3] Zhang, T.T., Tan, Y.F., Yang, H.X., Zhang, X.D. (2016). The application of air layers in building envelopes: A review. Applied Energy, 165: 707-734. https://doi.org/10.1016/j.apenergy.2015.12.108

[4] Tabet, I., Kezzar, M., Touafek, K., Bellel, N., Gherieb, S., Khelifa, A., Adouane, M. (2015). Adomian decomposition method and padé approximation to determine fin efficiency of convective straight fins in solar air collectors. International Journal of Mathematical Modeling \& Computations, 05(04): 335346. https://doi.org/10.13140/RG.2.2.12419.40483

[5] Ghasemi, S.E., Hatami, M., Ganji, D.D. (2013). Analytical thermal analysis of air-heating solar collectors. Journal of Mechanical Science and Technology, 27(11): 3525-3530. https://doi.org/10.1007/s12206-013-0878-0

[6] Marinca, V., Herisanu, N. (2008). Application of 
optimal homotopy asymptotic method for solving nonlinear equations arising in heat transfer. International Communications in Heat and Mass Transfer, 35(6): 710-715. https://doi.org/10.1016/j.icheatmasstransfer.2008.02.01 0

[7] Marincaand, V., Herisanu, N. (2008). Optimal homotopy asymptotic method with applications to thin film flow. Central European Journal of Physics, 6(3): 1608-1644. https://doi.org/10.2478/s11534-008-0061-x

[8] Erturk, V.S., Odibat, Z.M., Momani, S. (2012). The multi-step differential transform method and its application to determine the solutions of non-linear oscillators. Advances in Applied Mathematics and Mechanics, 4(4): 422-438. https://doi.org/10.1017/S2070073300001727

[9] Yaghoobi, H., Torabi, M. (2011). The application of differential transformation method to nonlinear equations arising in heat transfer. International Communications in Heat and Mass Transfer, 38(6): 815-820. https://doi.org/10.1016/j.icheatmasstransfer.2011.03.02 5

[10] Chen, X., Dai, Y. (2016). Differential transform method for solving Richards' equation. Applied Mathematics Mechanics, 37(2): 169-180. https://doi.org/10.1007/s10483-016-2023-8

[11] Kuo, B.L. (2005). Heat transfer analysis for the Falkner-Skan wedge flow by the differential transformation method. International Journal of Heat and Mass Transfer, 36(48): 5036-5046. https://doi.org/10.1016/j.ijheatmasstransfer.2003.10.046

[12] Khader, M., Megahed, A.M. (2014). Differential transformation method for studying flow and heat transfer due to stretching sheet embedded in porous medium with variable thickness, variable thermal conductivity, and thermal radiation. Appl. Math. Mech., 35(11): 1387-1400. https://doi.org/10.1007/s10483-0141870-7

[13] Salehi, P., Yaghoobi, H., Torabi, M. (2012). Application of the differential transformation method and variational iteration method to large deformation of cantilever beams under point load. Journal of Mechanical Science and Technology, 26(9): 2879-2887. https://doi.org/10.1007/s12206-012-0730-y

[14] Hatami, M., Ghasemi, S.E., Sahebi, S.A.R., Mosayebidorcheh, S., Ganji, D.D., Hatami, J. (2015). Investigation of third-grade non-Newtonian blood flow in arterie under periodic body acceleration using multistep differential transformation method. Appl. Math. Mech. Engl. Ed, 36(11): 1449-1458. https://doi.org/10.1007/s10483-015-1995-7

[15] Joneidi, A.A., Ganji, D.D. (2009). Differential transformation method to determine fin efficiency of convective straight fins with temperature dependent thermal conductivity. International Communications in Heat and Mass Transfer, 36(7): 757-762. https://doi.org/10.1016/j.icheatmasstransfer.2009.03.02 0

[16] Gorji, M., Hatami, M., Hasanpourand, A., Ganji, D.D. (2012). Nonlinear thermal analysis of solar air heater for the purpose of energy saving. Iranica Journal of Energy \& Environment, 3(4): 362-370. https://doi.org/10.5829/idosi.ijee.2012.03.04.10

[17] Chang, W., Wang, Y.F., Li, M., Luo, X., Ruan, Y.B., Hong, Y.R., Zhang, S.B. (2015). The theoretical and experimental research on thermal performance of solar air collector with finned absorber. Energy Procedia, 70: 13-22. https://doi.org/10.1016/j.egypro.2015.02.092

[18] Kalogirou, S. (2009). Solar energy engineeringprocesses and systems. Elsevier.

[19] Lina, W.X., Gao, W.F., Liu, T. (2006). A parametric study on the thermal performance of cross-corrugated solar air collectors. Applied Thermal Engineering, 26(10): 1043-1053. https://doi.org/10.1016/j.applthermaleng.2005.10.005

\section{NOMENCLATURE}

A

$\mathrm{c}_{\mathrm{p}}$

he

$\mathrm{hr}$

$\mathrm{S}$

$\mathrm{S}$

1 im

$\mathrm{m}$

Q

$\mathrm{T}$

W

U

D surface, $\mathrm{m}^{2}$

Specific heat, $\mathrm{J} \cdot \mathrm{Kg}^{-1} \cdot \mathrm{k}^{-1}$

convective-exchange coefficient, $\mathrm{W} \cdot \mathrm{m}^{-2} \cdot \mathrm{k}^{-1}$

radiative-exchange coefficient, $\mathrm{W} \cdot \mathrm{m}^{-2} \cdot \mathrm{k}^{-1}$

channel height, $\mathrm{m}$

solar intensity, w. $\mathrm{m}^{-2}$

length of the collector, $\mathrm{m}$

mass flow, Kg.s $\mathrm{s}^{-1}$

Mass, $\mathrm{kg}$

heat flow, w

time, $\mathrm{s}$

temperature, ${ }^{\circ} \mathrm{C}$

width of the collector, $\mathrm{m}$

loss coefficient, $\mathrm{W} \cdot \mathrm{m}^{-2} \cdot \mathrm{k}^{-1}$

hydraulic diameter, $\mathrm{m}$

\section{Greek symbols}

$\begin{array}{ll}\alpha_{\mathrm{P}} & \text { Absorbance } \\ \eta_{\mathrm{T}} & \text { Theraml efficiency } \\ \tau & \text { transmittance } \\ \lambda & \text { thermal conductivity } \mathrm{W} \cdot \mathrm{m}^{-1} \cdot \mathrm{k}^{-1} \\ \delta & \text { thickness, }(\mathrm{m})\end{array}$

Subscripts

a

$\mathrm{b}$

$\mathrm{p}$

$\mathrm{g}$

in

$\mathrm{p}$

$\mathrm{L}_{\mathrm{i}}$
Ambient
back plate
absorber plate
glass cover
insulator
absorber plate
Derivative operator 